\title{
Dotación artística de la Iglesia de Santa María de Sábada de Lastres. Obras datadas en la Edad Moderna
}

Milca Iglesias Echevarría

RESUMEN:

El presente artículo pretende hacer una revisión de las obras artísticas de la Edad Moderna que aún hoy se conservan en la iglesia parroquial de Santa María de Sábada, en Lastres. Hasta el momento se han publicado varios estudios sobre el tema, si bien no se tenían referencias documentales que esclareciesen la autoría y procedencia de algunas de las piezas. Gracias a un trabajo reciente, hoy podemos datarlas y atribuirlas a artistas tan reconocidos como Bernardo de la Meana o Antonio de Borja. Asimismo, podemos revelar la procedencia de algunas otras, donadas por los comerciantes lastrinos de la época.

PALABRAS CLAVE:

Lastres, Edad Moderna, Santa María de Sábada, Bernardo de Meana, Antonio de Borja.

\section{ABSTRACT:}

This article expects make a review of the artistic objects dated on early modern period that still today remains in the parish church of Santa María de Sábada, in Lastres. Until today it has been published several studies on the topic, although there were no documentary references that clarify the authorship and origin of some of the pieces. Thanks to a recent work, today we can date and attribute them to such recognized artists like Bernardo de la Meana or Antonio de Borja. Likewise, we can reveal the origin of some others, donated by the enriched traders born in Lastres of the period.

\section{KEY WORDS:}

Lastres, Edad Moderna, Santa María de Sábada, Bernardo de Meana, Antonio de Borja. 
La villa de Lastres, ubicada en el concejo de Colunga, en la zona oriental del Principado de Asturias, es conocida por su paisaje, calificado como pintoresco, y por ser uno de los lugares más visitados por los foráneos en la región. Sin embargo, pocas veces se habla del magnífico patrimonio que conserva el lugar; tanto laico como eclesiástico, tanto mueble como inmueble. En este artículo nos centraremos en el análisis de las obras artísticas de la Edad Moderna de la iglesia parroquial, partiendo de otros estudios realizados sobre el mismo, y aportando nuevos datos sobre las obras de relevancia artística que hasta ahora no habían sido fechadas $o$ atribuidas.

\section{Breve reseña histórica sobre la fábrica parroquial dieciochesca}

El actual edificio data de la segunda mitad del siglo XVIII, si bien con anterioridad los vecinos contaban ya con un templo a las afueras de la villa. Este se encontraba en un paraje de difícil acceso, inhóspito e inseguro por lo que desde 1676 el vecindario pidió que fuese trasladado al puerto ${ }^{1}$. La empresa se vio paralizada durante mucho tiempo, probablemente en pro de las obras del muelle y debido a los numerosos enfrentamientos entre los vecinos de Lastres y Luces, quienes no se ponían de acuerdo en la ubicación del nuevo edificio. No fue hasta 1752 cuando la Real Audiencia del Principado de Asturias tomó la decisión definitiva: la iglesia de Santa María de Sábada se trasladaría al puerto de Lastres y, específicamente, al lugar denominado de "El Fontanín"2. Asimismo, los autos judiciales dictaban que las trazas debían encargarse a un maestro reputado y de sobrada experiencia, designándosele la empresa a Pedro Antonio Menéndez (1716-1790) a quien, poste-

\footnotetext{
AHN, Consejos 28103, Exp. 5, f. 1 (1676).

De hecho un año más tarde, en 1677, Domingo González García trazó los planos de una iglesia que nunca llegó a realizarse.

AHN, Consejos MPD 2424r y 2425r.

2 Archivo privado. Pleito de Luces y Lastres sobre la traslación de la iglesia parroquial. Autos ganados a favor de los vecinos de Lastres, s/f. 15 de marzo de 1754.

De la iglesiona vieya se acarreó material para la nueva construcción, así como algunas piezas litúrgicas tales como dos pilas de agua bendita decoradas con veneras y hojas lanceoladas y que hoy se encuentran según accedemos al templo, a ambos lados.
}

riormente, también se propuso como candidato para reedificar el muelle lastrino ${ }^{3}$.

La obra de la iglesia salió a remate en el año $1756^{4}$, colocándose la primera piedra dos años más tarde ${ }^{5}$ y siendo bendecida el 27 de marzo de $1765^{6}$, si bien faltaba el cierre de los pies, el cual se realizaría con posterioridad ${ }^{7}$. Todo ello pudo llevarse a cabo gracias a la generosidad de las familias Robledo Colunga y Menéndez Villar, quienes habían adquirido una importante fortuna por su labor como comerciantes internacionales ${ }^{8}$.

\section{Dotación artística del templo}

Por desgracia, la mayor parte de las donaciones y encargos que se realizaron para alhajar la iglesia durante la Edad Moderna han desaparecido por motivos bélicos, si bien, como veremos a continuación, algunas de las obras que hoy se custodian en ella pertenecen a esa época. La información con la que contamos sobre el amueblamiento interior del edificio a finales del siglo XVIII es escasa. A pesar de ello, en las siguientes páginas haremos un análisis y revisión de las obras, principalmente escultóricas, de la Edad Moderna que hoy encontramos en la iglesia, por orden cronológico. Algunas de ellas se han podido documentar mientras que otras se ha podido atribuir gracias a un examen estilístico.

La primera obra de la que tenemos que hablar es la imagen de bulto redondo de Santo Domingo de Guzmán (110 x 52 x 30 cm. aprox.). Los vecinos de la localidad siempre se han re-

\footnotetext{
Archivo privado. Acarreo de la iglesia vieja y órdenes para la planta nueva, s/f. 1754.

4 Archivo privado. Remate de la obra de la iglesia, s/f. (28 de octubre de 1756).

5 Archivo privado. Datos de la nueva iglesia, s/f. (1758).

6 Archivo privado. Testimonio de bendición y uso de la iglesia, s/f. (27 de marzo de 1765).

7 Primeramente en 1775 se colocó una espadaña y años más tarde, en el primer tercio de la década de 1790, se levantó la torre campanario que se conserva actualmente.

MADRID ÁLVAREZ, V. de la, La arquitectura de la Ilustración en Asturias. Manuel Reguera (1731-1798), Oviedo, Real Instituto de Estudios Asturianos, 1995, pp. 284-287.

Archivo privado. Carta de José Robledo a su hermano Lorenzo Antonio Robledo Colunga. Lima, 20 de mayo de $1793, \mathrm{~s} / \mathrm{f}$.

8 IGLESIAS ECHEVARRÍA, M., "Los hermanos Robledo. Mecenas de arte en Lastres”, Liño, n² 20, Oviedo, Universidad de Oviedo, 2014, pp. 59-68.
} 
ferido a ella erróneamente como San Vicente Ferrer y muy probablemente sea la pieza que Germán Ramallo en su obra sobre la escultura barroca asturiana dató en el siglo XVIII ${ }^{9}$. Está ubicada en uno de los machones del lado del Evangelio. El santo se presenta en pie, afrontado y con rostro inexpresivo, ataviado con la vestimenta propia de la Orden. Con el brazo izquierdo sostiene el tallo de un lirio mientras que con la mano contraria ase un libro, cerrado. La imagen, con abundante plegado de las ropas, siempre vertical y poco audaz, nos señala una clara filiación al estilo de Luís Fernández de la Vega (1601-1675), siendo una más que probable escultura emanada de alguno de sus seguidores, bastante más limitados que su maestro. Estaríamos, por tanto, ante un trabajo del último tercio del siglo XVII, una pieza traída de algún otro lugar hasta el templo parroquial tras la Guerra Civil.

Lo mismo sucedió con la imagen de San Roque (68 x 34 x 18,5 cm., con peana), que desde hace unos años se encuentra en la sacristía de la iglesia. Originariamente se encontraba en la ermita de igual advocación, situada en la zona alta de la villa y construida en el segundo tercio del siglo XVII, con carácter comunal. Se trata de un San Roque de pequeñas dimensiones: un varón de mediana edad, ataviado como peregrino y acompañado por un perro. Con la mano zurda recoge el ropaje para dejar ver los bubones de la peste.

Si bien no podemos precisar su cronología o autoría documentalmente, por su factura podemos inscribirlo en el entorno de Antonio Borja (h. 1661-1730) y datarlo, por tanto, a finales del siglo XVII o principios ya del siglo siguiente. Se trataría de una obra realizada por alguno de sus seguidores, que no por el maestro mismo, quien en el San Roque de la iglesia de La Corte de Oviedo emplea un canon mucho más esbelto y elegante ${ }^{10}$.

También en la sacristía del templo nos encontramos con tres Crucificados de buena calidad, especialmente dos de ellos de ellos. El pri-

RAMALLO ASENSIO, G., Escultura barroca en Asturias, Oviedo, Real Instituto de Estudios Asturianos, 1985, p. 573.

10 RAMALLO ASENSIO, G., Escultura barroca..., opus. cit., p. 302.

Mi agradecimiento más sincero al profesor Germán Ramallo Asensio, quien amablemente aclaró mis dudas sobre esta y otras escultura que se mencionarán en este artículo. mero al que haremos referencia se trata de una pequeña imagen de Cristo Crucificado (30,5 x 30,5 x $11 \mathrm{~cm}$.) de tres clavos. La talla es cuidada, de ejecución muy acabada. Recuerda, de nuevo, a obras de Antonio Borja y su taller tales como el Crucificado de Santa María de Laspra o el de las agustinas de Oviedo ${ }^{11}$. De dicho maestro el autor de la pieza toma la expresión corporal y angustiosa, así como la anatomía esbelta y delgada, dejando clara la parte ósea, recubierta por músculos poco desarrollados pero lo suficientemente tensos. Además, y siendo esta otra de las particularidades de Borja, se dejan al descubierto los huesos de la cintura pélvica. Esta atribución viene apoyada por un documento consultado recientemente, en el cual se registra el inventario de bienes del matrimonio lastrino formado por Magdalena Victorero y Cosme González (1708-1743 activo), quien regentó durante décadas una próspera compañía comercial en Vigo. En la escritura se habla de "un crucifijo con un San Francisco y un San Antonio de Padua hechura de Borja"

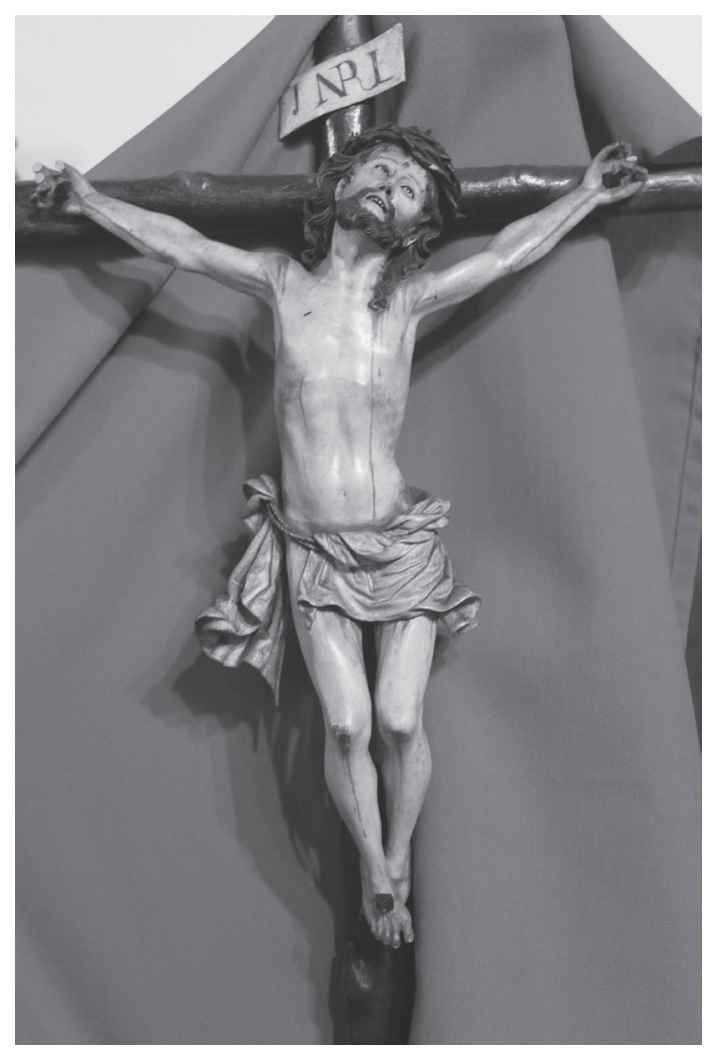

Fig. 1. Crucificado. Atribuido a Antonio de Borja.

Íbidem, p. 337.

12 AHA, PN de Villaviciosa, Caja 1298/08, f. 66r (Inventario de bienes ante Pedro Balbín, 1743). 


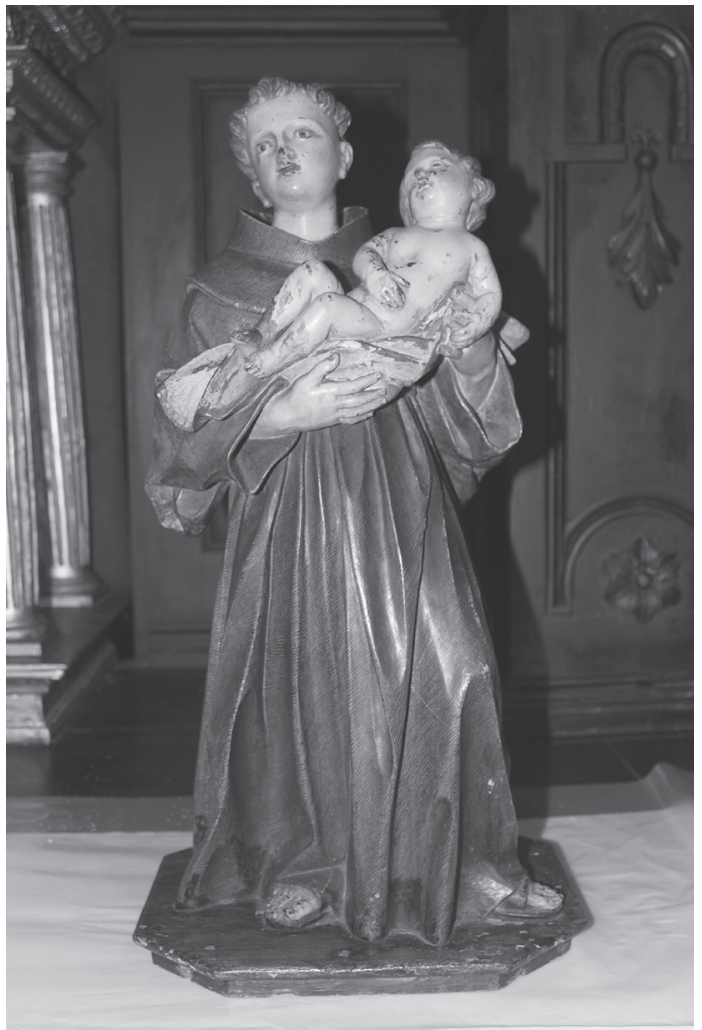

Fig. 2. San Antonio de Padua con el Niño. Atribuido a Antonio de Borja.

El hecho de que fuese un encargo privado sería el motivo, además, que justificaría algunos rasgos que hacen diferente esta pieza de otras de Borja: es un Cristo con un acabado muy cuidadoso, a modo casi de marfil policromado, y los ojos, más achinados de lo habitual en el maestro, están realizados con cristal, material no empleado en su taller.

En el documento mencionado se hacía referencia, también, a un San Antonio de Padua, que identificamos con una talla que se conserva actualmente en la iglesia (62 x 32 × 27,5 $\mathrm{cm}$.). Se trata de un pequeño grupo escultórico realizado en madera, en el que se representa al santo con el Niño ${ }^{13}$. La figura de San Antonio, ataviado como franciscano, se encuentra erguida, en una posición de ofrenda y sosteniendo a Jesús en brazos. Este, echado sobre un paño, gira completamente el cuerpo, mirando al cielo.

13 En un primer momento Germán Ramallo fechó esta obra en la segunda mitad del siglo XVIII, aludiendo que seguía una clara estética rococó. Ahora, gracias a la documentación encontrada, debemos adelantar dicha datación. RAMALLO ASENSIO, G., Escultura barroca..., opus. cit., p. 573.
Un estudio comparativo, para el que recurrimos a otras obras atribuidas por Ramallo a Antonio de Borja ${ }^{14}$, corrobora esta atribución. Es cierto que en la talla de la Virgen con el Niño de la capilla del Palacio de Meres (Siero) o la de San José con el Niño de la parroquia ovetense de San Isidoro, el pequeño se encuentra erguido con la espalda recta, lejos de la graciosa posición del Niño de este San Antonio. Sin embargo, en la imagen de la Virgen del Valle del retablo mayor de la colegiata de Pravia, atribuido al mismo artista en 1725 y que sigue el modelo de la Virgen del Valle de San Juan Bautista Portigiani, el Niño figura echado en el regazo de la madre y tiene un movimiento gracioso, aunque no llega a alcanzar la inestabilidad del modelo de Lastres, tal vez por ser este posterior ${ }^{15}$.

El segundo Crucificado $(72 \times 40 \times 10 \mathrm{~cm}$. aprox.) dentro de la sacristía, al que hemos hecho alusión anteriormente, es más tardio en cuanto a cronología. De nuevo estamos ante un Cristo vivo de tres clavos, pero de complexión y postura mucho más marcada y escorzada, más en la estética madrileña de Luís Salvador de Carmona (1708-1767) de anatomías veristas pero un tanto delicadas e idealizadas. Estas similitudes nos permiten fechar la obra a partir del segundo tercio del siglo XVIII.

Sabemos que dentro de la iglesia primigenia se levantaron varias capillas con advocaciones diferentes. Una de ellas fue la dedicada a la Virgen del Carmen, algo lógico por ser Lastres una villa eminentemente marinera. Ya en 1760, y estando aún el templo en fase de construcción, el comerciante Joseph Ysla (1720-1760 activo), enriquecido en Galicia debido al comercio internacional con Inglaterra, mandó hacer un retablo y una imagen para dicha capilla mariana $^{16}$. Suponemos que la manda se llevase a cabo puesto que años más tarde su viuda, Rosa Suárez Cantillo, hablaba de “(...) la Virgen del Carmen que tengo encargada para colocar en la iglesia parroquial (...)”17. Probablemente

14 Íbidem, pp. 325, 326 y 328, figs. 208 y 215.

15 Íbidem, p. 324, fig. 205; GONZÁLEZ SANTOS, J., “El escultor florentino Juan Bautista Portigiani. Noticias de sus obras en Asturias", Boletín del Seminario de Estudios de arte y Arqueología, LII, Valladolid, 1986, pp. 297-310.

16 AHA, PN de Villaviciosa, Caja 1313/01, nº 155 (Testamento ante Manuel Álvarez, 11 de febrero de 1760).

17 AHA, PN de Villaviciosa, Caja 1317/Legajo de testamentos 3, n 101 (Copia del testamento realizado el 11 de marzo de 1762 ante Manuel Álvarez, 1765). 
esta imagen se corresponda con la Virgen del Carmen de vestir $(120 \times 45 \times 30 \mathrm{~cm}$.) que se conserva actualmente en el templo, la cual podemos considerar de estilo barroco popular y cuyas características no le confieren un gran valor artístico.

Otra de las capillas que se erigió en el siglo XVIII en la iglesia parroquial fue la de Santa Teresa y Santo Toribio, sufragada por Theresa Rita Robledo Colunga (1713-1751) y Thoribio Menéndez Villar (1693-1750) y ubicada en el lado de la Epístola del edificio. El matrimonio, enriquecido gracias al comercio de la sal en Galicia y a las compañías mercantiles que regentaron en Vigo y Santiago de Compostela, fueron grandes mecenas de la villa.

Nos interesa especialmente el hecho de que el testaferro de la benefactora, el abad de San Isidoro de León Joseph Antonio de Goiri, encargase el 6 de septiembre de 1764 un sencillo retablo para embellecer dicho oratorio al "Maestro tallista y estatuario de la Catedral"18, al que se le pagarían tres mil treinta y siete reales de vellón por la obra ${ }^{19}$. Este cargo lo ocupaba, para aquel entonces, José Bernardo de la Meana (1715-1790), formado en Madrid y considerado el último gran escultor barroco asturiano antes de la llegada del influjo de la Academia $^{20}$. En el retablo se albergaron "las efigies de Santa Teresa y Santo Toribio", por cuya hechura se pagaron al maestro quinientos reales, más doscientos por pintarlas y dorarlas ${ }^{21}$. Esta información nos interesa especialmente ya que nos permite atribuir a Bernardo de la Meana la escultura de Santo Toribio de Astorga que actualmente se halla en la iglesia lastrina, dato hasta ahora desconocido.

18 ACSILeón, N-C.c: Fundaciones piadosas, benéficas, varias, Caja 152, Leg. 7 (6 de septiembre de 1764).

19 ACSILeón, N-C.c: Fundaciones piadosas, benéficas, varias, Caja 152, Leg. 18, ff. 1, 2 (2 de mayo de 1767).

20 RAMALLO ASENSIO, G., Escultura barroca..., opus. cit., pp. 448-480; MADRID ÁLVAREZ, V. de la, "La Biblioteca de José Bernardo de la Meana, escultor y arquitecto asturiano de la segunda mitad del siglo XVIII", Academia, Boletín de la Real Academia de Bellas artes de San Fernando, 75, Madrid, 1992, pp. 423-434. El costo del retablo nos indica que debía ser una pieza de dimensiones modestas puesto que por los encargados al mismo autor unos años antes (Puerto de Vega en 1747 y Grao en 1748) se le pagaron doce mil reales de vellón en cada caso.

RAMALLO ASENSIO, G., Escultura barroca..., opus. cit., p. 464.

21 ACSILeón, N-C.c: Fundaciones piadosas, benéficas, varias. Caja 152, Leg. 7, f.1.

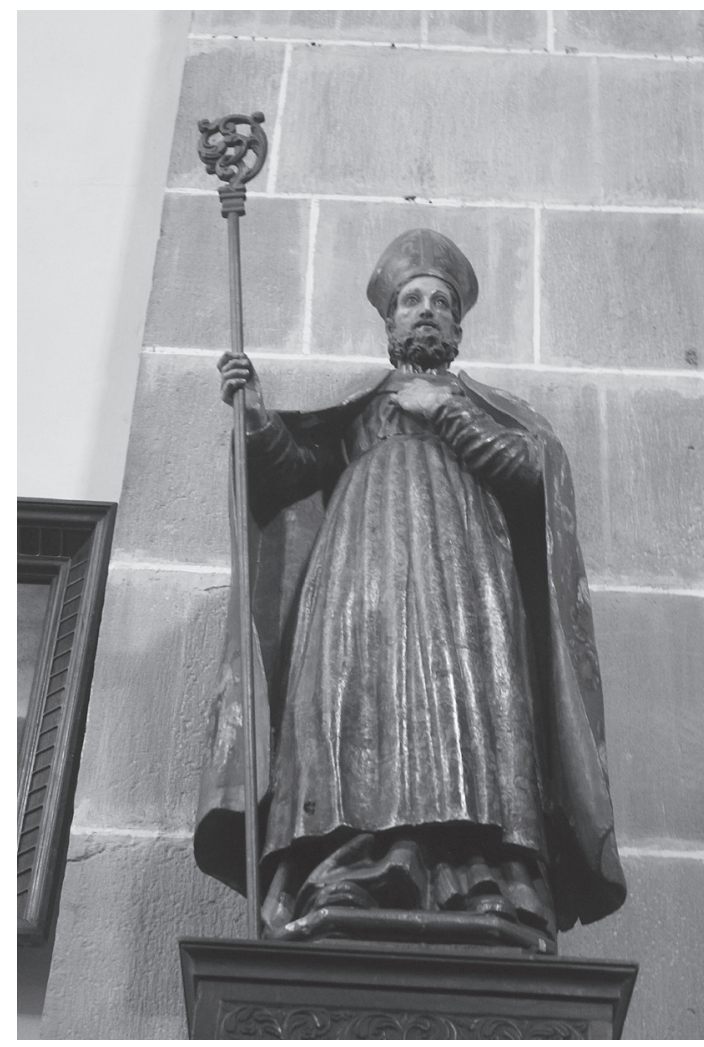

35

Fig. 3. Santo Toribio de Astorga. Atribuido a Bernardo de la Meana.

Se representa al santo en pie, afrontado, vestido como obispo. Los brazos están separados del tronco, flexionados, con manos de gruesos dedos; con la derecha sostiene el báculo y la izquierda la apoya sobre el pecho, en actitud piadosa. Es un santo de rostro bastante expresivo: ojos almendrados mirando al cielo, con bolsas bajo los mismos, nariz larga y recta y boca pequeña, ligeramente entreabierta y enmarcada por arrugas de expresión. El cabello, en mechones ondulados de poco volumen, es oscuro y adquiere una mayor relevancia en la barba.

Si hacemos una comparativa de esta imagen con las que el mismo autor realizó para decorar la girola de la catedral de Oviedo, encontramos claras similitudes. Una de las características que definió la obra de Meana fue su insistencia en lo expresivo, conseguida a través del gesto facial, las arrugas y el tallado minucioso del cabello y la barba ${ }^{22}$. Este rasgo queda claro en la imagen que nos ocupa, la cual recuerda mucho al San Jerónimo o al profeta Isaías que esculpió para el enclave ya mencionado. Los tres per-

22 RAMALLO ASENSIO, G., Escultura barroca ..., opus. cit., p. 455. 
sonajes tienen rasgos faciales muy similares: ojos vítreos de mirada perdida, larga nariz recta, bocas entreabiertas, pómulos sobresalientes que hunden aún más las cuencas de los ojos y arrugas de expresión tanto alrededor de los mismos como de la boca. Además, aunque en el caso lastrino la barba del obispo es más modesta y recortada, sigue siendo igual de enjuta que en las otras dos piezas.

Asimismo, las esculturas de José Bernardo de la Meana suelen ir ataviadas con ropajes muy abundantes, de pliegues numerosos y blandos $^{23}$. Si de nuevo analizamos comparativamente la imagen lastrina con las de la catedral, encontramos similitudes más que obvias: el vuelo y vaciado del manto nos pueden recordar al San Jerónimo ya mencionado y, más aún, al ropaje de San Juan Crisóstomos, ubicado también en la girola ovetense. En cuanto a la posición de las manos, la postura adquirida por Santo Toribio es prácticamente idéntica a la que mantiene la escultura de San Blas que Meana hizo igualmente para la catedral de Oviedo. La mano izquierda se coloca abierta sobre el pecho, a la altura casi del cuello, con un ligero movimiento en el dedo meñique. La contraria, despegada del cuerpo, cierra delicadamente los dedos sobre sí mismos para sostener el báculo.

Probablemente como los vecinos eran sabedores de la calidad de la imagen, esta se ocultó durante la guerra y fue trasladada a la antigua capilla del Rosario y San Blas, hoy desaparecida.

En la iglesia actual nos encontramos otra capilla dedicada al Santo Cristo de la Agonía cuya advocación inicial fue la de San José24. En ella, situada en el lado del Evangelio del templo, se custodia un gran retablo de piedra artificial que, si bien se escapa de la cronología que nos ocupa en este artículo, tiene una cierta relevancia pues está firmado por Manuel del Busto (1874-1948) y Juan Manuel del Busto (1904-1967). Padre e hijo fueron los grandes arquitectos de la primera mitad del siglo XX en Asturias, dejando atrás los historicismos $\mathrm{y}$ academicismos imperantes en la región e introduciendo un lenguaje más internacional y moderno ${ }^{25}$.

Íbidem, p. 456.

24 AHA, PN de Villaviciosa, Caja 1330/03, ff. 39, 40 (10 de junio de 1794).

25 Sobre dichos arquitectos existen más estudios como FAES HERNÁNDEZ, R., Manuel y Juan Manuel del Busto, arquitectos, Madrid, Universidad Complutense
Aunque no hay ningún documento que permita datar este retablo de forma exacta, lo lógico sería pensar que hubo de realizarse tras 1943, puesto que en el inventario parroquial de dicho año no aparece ${ }^{26}$, y antes de 1948, año de la muerte de Manuel del Busto. Casi con toda seguridad, la pieza fue diseñada y esculpida con la intención de contener dos de las piezas de mayor importancia que encontramos en la iglesia: un frontal de cordobán de procedencia americana y la talla del Santo Cristo de la Agonía. Este hecho viene confirmado, además, por la inscripción que se recoge en el ático del retablo aludiendo al Crucificado, así como por los elementos decorativos alusivos al martirio de Cristo y por las pinturas de motivos vegetales que imitan el cuero del frontal de altar.

Refiriéndonos al frontal de cordobán, de excelente calidad y tan escaso en el norte de España, se encuentra actualmente recortado y superpuesto sobre un panel de madera. Se trata de un trabajo en cuero repujado y policromado, previsiblemente perteneciente a un taller americano si atendemos a los elementos decorativos que lo recorren: frisos de jarrones vegetales de cuyas bocas brotan rosas, camelias y flores acampanadas en tonos dorados y anaranjados, bajo palios dorados. Teniendo esto en cuenta, lo más lógico sería que la pieza se corresponda con el frontal de puerta que José Robledo Colunga envió desde Lima en el año $1793^{27}$. Este, junto con dos pequeñas lámparas de plata que están colgadas en el presbiterio del templo, son los únicos donativos que se conservan de entre el sinfín de alhajas que el coronel Robledo envió desde Perú y que, por desgracia, fueron ex-

de Madrid, 1982 y Manuel del Busto, arquitecto, 18741948, Oviedo, Colegio Oficial de Arquitectos de Asturias, 1997. Igualmente, puede consultarse MADRID ÁLVAREZ, V. de la, "Noticias sobre la obra de los arquitectos Manuel del Busto y Miguel de la Guardia en Avilés", en Liño, nº. 8, Oviedo, Universidad de Oviedo, 1989, pp. 129-146.

26 Archivo Parroquial de Lastres, Parroquia de Santa María de Sábada, Inventario de la iglesia de Lastres (diciembre de 1943), s/f.

27 Archivo privado. Carta de José Robledo a su hermano Lorenzo Antonio Robledo Colunga. Lima, mayo de 1793. La bibliografía sobre este tipo de piezas no es muy amplia, si bien podemos mencionar FERRANDIS TORRES, J., CORDOBANES Y GUADAMECÍES. Catálogo ilustrado de la Exposición, Madrid, Sociedad Española de Amigos del Arte, 1943; MIRANDA CASTILLO, E., "Algunos alcances para el estudio de la artesanía en cuero", en Escritura y Pensamiento, Año IX, nº. 19, Lima, Universidad Nacional Mayor de San Marcos, 2006, pp. 79-98. 


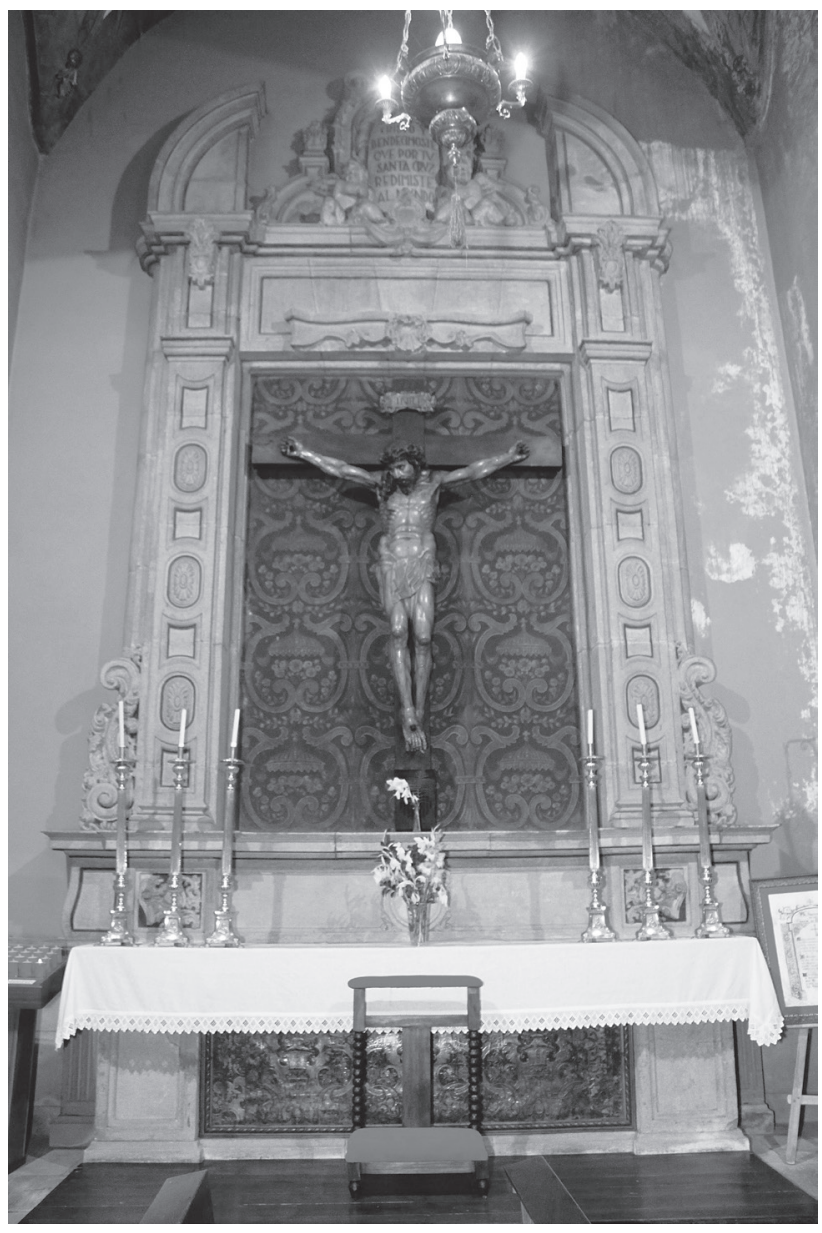

poliadas durante la Guerra Civil. José Antonio Robledo Colunga (1720-1803/6), ingeniero en la mina de Potosí y comerciante en el virreinato del Perú, fue el que costeó gran parte del nuevo templo parroquial de Lastres en la segunda mitad del siglo XVIII.

Por su parte, la imponente talla del Cristo de la Agonía se asienta sobre una arbórea cruz posterior, encargada en $1938^{28}$. La talla es de gran calidad y ejecución muy cuidada: Cristo en expiración, de anatomía verista, complexión musculosa y robusta y expresivo rostro. Sobre su autoría o pertenencia a una u otra corriente artística, se ha especulado mucho: algunos lo han atribuido a la escuela renacentista de finales del siglo XVI, otros han considerado la pieza plenamente barroca ${ }^{29}$ y Germán Ramallo

28 Se pagaron treinta mil pesetas por ella. Archivo Parroquial de Lastres, Parroquia de Santa María de Sábada, Libro de fábrica (1937-1979), f. 2r (1938).

29 CABAL VIESCAS, A. J., Arte por concejos. Caravia, Colunga y Villaviciosa, Oviedo, Cajastur. Obra Social y Cultural, 2003, pp. 28, 29. ha sugerido datarlo a principios del siglo XVIII teniendo en cuenta el intenso dramatismo de la figura, aunque avisa de que desde el punto de vista de la forma habría que retrasar esta fecha ${ }^{30}$. Lo cierto es que poco o nada se conocía de su procedencia hasta que recientemente se han encontrado unos documentos con fecha de 4 de marzo de 1767 en los que el mayordomo de la iglesia parroquial de Lastres escribía lo siguiente, probablemente refiriéndose a la pieza que nos ocupa: “(...) que por cuanto Don Juan Antonio Batalla, natural de esta vecindad, vezino que fue de la villa de Pontevedra, reyno de Galicia, al presente difunto, hizo donación y sufragó a esta dicha iglesia una soberana imagen de Nuestro Señor Redemptor Jesuchristo Crucificado (...)"31. El referido Juan Antonio Batalla (1728-1750 activo) fue uno de los mu-

30 RAMALLO ASENSIO, G., Escultura barroca..., opus. cit., p. 391.

31 AHA, PN de Villaviciosa, Caja 1325/07, s-7f. (Escritura ante Toribio Ruiz, 4 de marzo de 1767). 
chos y reputados comerciantes lastrinos afincados en Pontevedra, emparentado además con otra de las familias pudientes de comerciantes emigrados: los Mariqueta.

En ningún momento se dice que el comerciante o su esposa encargasen la obra, por lo que bien pudo ser una pieza adquirida, cabiendo la posibilidad de que hubiese sido elaborada antes del momento de la compra. Entendemos, eso sí, que el Crucificado tenía que ser una imagen lo suficientemente importante en cuanto a calidad como para que los mecenas hubiesen decidido conducirla desde Galicia hasta Lastres, en vez de encargar su hechura en el propio Principado. Teniendo en cuenta este hecho, podríamos adscribir la obra a la escuela gallega del siglo XVII avanzada que mantiene vivo el patetismo de la escuela de Francisco de Moure, y entroncando incluso con el del Maestro de Sobrado ${ }^{32}$.

No tenemos mucha documentación más que hable del interior de la iglesia dieciochesca salvo las órdenes que en 1790 José Antonio Robledo Colunga daba a su hermano y párroco de Lastres Lorenzo Antonio Robledo Colunga (1711/5-1794), por escrito, sobre las donaciones que estaba enviando desde América, donde comerciaba y servía como Director de las Reales Minas de Oro y Plata del Potosí. Pedía que con ciertas cantidades de dinero se realizasen los altares mayor y laterales de la iglesia: de yeso "con todo aseo, a la moderna, sin perifollos de antigüedad (...). Las efigies han de ser de cuerpo entero, de mucho aseo" ${ }^{\text {"3 }}$. Los retablos no se realizaron en aquel momento, muy probablemente porque el dinero enviado desde América estaba siendo invertido en las obras de la torre de la nueva iglesia. Dos años más tarde, en 1792, se pidió a Francisco Castellote, maestro levantino experto en yeso y bóvedas, que diese alguna recomendación al respecto ${ }^{34}$ pero no fue hasta un año más tarde, el 22 de julio de 1793, cuando se firmó el contrato para que los her-

32 Mis agradecimientos a los profesores Javier González Santos y Julio J. Polo Sánchez por orientarme con distintos comentarios al respecto.

33 Archivo privado. Carta de José Robledo a su hermano Lorenzo Antonio Robledo Colunga. Lima,5 de noviembre de $1790, \mathrm{~s} / \mathrm{f}$.

Hay que recordar, además, que en 1777 Carlos III había promulgado una circular en la que se prohibía el uso de madera para los retablos en pro de materiales que representasen un menor peligro ante un incendio.

34 Archivo privado. Recomendaciones para el retablo mayor, s/f. (27 de marzo de 1792). manos Miguel y Agustín Raimundo López Acevedo realizasen las estructuras ${ }^{35}$. Estos, oriundos de Tapia de Casariego y estudiados por Germán Ramallo Asensio en su obra ${ }^{36}$, ya estaban formados en la estética de la Academia de San Fernando bajo el nuevo ideal contra el barroco decorativo y, por tanto, podían responder a la exigencia del mecenas de que las piezas fuesen limpias y modernas.

El retablo mayor, según el contrato ya mencionado, debía estar compuesto por cuatro columnas jónicas, sobre las que se alzaría un frontispicio de igual orden, coronado por un haz de ráfagas de madera dorada, flanqueadas estas por dos ángeles de yeso, blancos. Esta estructura, a modo de templo clásico, albergaría una hornacina central donde se dispondría una imagen, igualmente realizada en yeso blanco, de la Purísima Concepción. Por su parte, sobre los retablos laterales solamente se especificaba que debian ser de menores dimensiones y realizarse con idénticos materiales y técnicas.

El retablo mayor que encontramos hoy en la iglesia de Santa María de Sábada parece ser una copia casi idéntica del retablo neoclásico original descrito. Se puede afirmar esto basándonos en diferentes informaciones: por una parte, la documentación parroquial deja constancia de que debido a la Guerra Civil prácticamente se perdieron todas las obras mueble de la parroquia, dato corroborado por los testimonios orales de los vecinos del lugar, que no tratamos como fiables plenamente. Asimismo, sabemos a ciencia cierta que en 1943 la iglesia tenía ya reconstruido su retablo mayor en el presbiterio ${ }^{37}$. Comparando una fotografía del retablo anterior al conflicto bélico con el actual, percibimos pequeñas diferencias entre ambas estructuras, si bien son mínimas por lo que sería lógico pensar que la pieza sufrió algún tipo de destrozo en la guerra, subsanado con rapidez, pero que no supuso la desaparición total de la obra.

Se trata de un retablo en el que la estructura arquitectónica predomina con respecto a la estatuaria, de estilo ya clásico y modelo adaptado a la estética impuesta en el momento desde Madrid por la Academia de San Fernando. No en

35 AHA, PN de Villaviciosa, CAJA 1335/04, nº 74 (Contrato ante José Lorenzo Isla, 22 de julio de 1793).

36 RAMALLO ASENSIO, G., Escultura barroca ..., opus. cit., pp. 511-513.

37 Archivo Parroquial de Lastres, Parroquia de Santa María de Sábada, Inventario de la iglesia de Lastres (diciembre de 1943), s/f. 


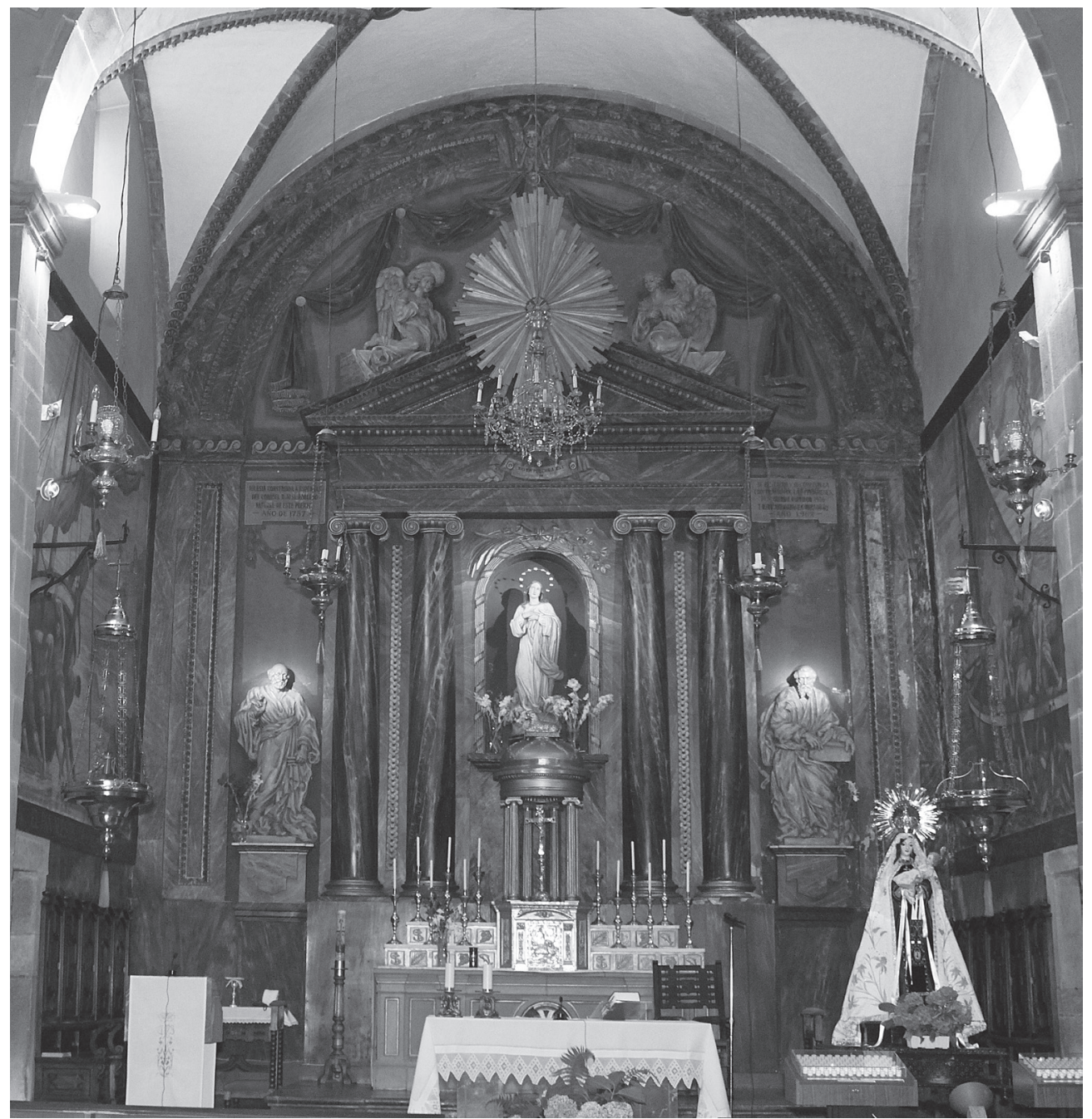

Fig. 5. Retablo mayor. Obra de los hermanos López Acevedo.

vano cabe destacar que dicha institución había difundido en 1792 la obra de Ramón Pascual Díez titulada Arte de hacer el estuco jaspeado o de imitar los jaspes a poca costa y con la mejor propiedad $^{38}$, a la que se alude en el contrato firmado entre Lorenzo Robledo Colunga y los hermanos López Acevedo.

38 PASCUAL DÍEZ, R., Arte de hacer el estuco jaspeado ó de imitar los jaspes á poca costa y con la mayor propiedad, Madrid, Imprenta Real, 1785.

Sobre la obra se han realizado estudios posteriores tales como GABRIEL NAVARRO, J., "Arte de hacer estuco, escrito en el siglo XVIII por Don Ramón Pascual Díez", en Archivo español de arte y arqueología, Tomo 8, ${ }^{\circ}$. 24, Madrid, Centro de Estudios Históricos, 1932, pp. 237-242.

Igualmente, la edición facsímil del tratado impresa en Valladolid en 1988 incluye un estudio de J.R Nieto González titulado "El tratadista Don Ramón Pascual Díez. Su vida, obra y época”.
Actualmente el retablo ocupa todo el lienzo principal de la capilla mayor del templo ${ }^{39}$, de orden gigante y tres calles. Se aprovecha el muro, sobre el que se apoyan dos pilastras cajeadas, de yeso, en las que se desarrolla un gran arco de medio punto, decorado con elementos vegetales dorados. En la clave figura un ángel alado. Sobre el banco, liso, se alza el cuerpo principal del retablo, a modo de templete clásico. Una hornacina central, con remate en arco de medio punto, se halla flanqueada por cuatro columnas jónicas, imitando jaspe verde y con capitel dorado. En ella se custodia la imagen de la Purísima Concepción, no siendo esta la origi-

$39 \quad$ En los lienzos laterales podemos contemplar sendos murales realizados por los hermanos Uría Aza en el año 1962. En ellos se representan pasajes de la vida de Cristo y sus apóstoles relacionados con la pesca y la vida cotidiana de los marineros. 
nal sino una posterior de pasta de madera. Sobre las columnas se sitúa el arquitrabe escalonado, con friso liso con inscripción, y rematado con frontón triangular. Los ángeles de escayola, imitando el aspecto pétreo y de estética mucho más barroca que el retablo, culminan el conjunto. Un estilo similar siguen las esculturas de las calles laterales: San Pablo y San Pedro, cuya fuente de inspiración bien pudieran haber sido las homónimas imágenes en piedra de la girola de la catedral de Oviedo elaboradas por Manuel Pedrero, si bien las lastrinas tienen un empaque que recuerda más a obras de mayor alcurnia como las esculturas realizadas para San Juan de Letrán por Giuseppe Mazzuoli (1644-1725), salvando las distancias ${ }^{40}$.

En el contrato también quedaba establecido que el retablo albergaría, como es lógico, un sagrario cuya puerta “(...) se hará de madera bien que si los dichos señores dueños de la obra ideasen de otra materia se hará de su cuenta" ${ }^{41}$. Efectivamente, se hizo así y se colocó una puerta de plata, parcialmente sobredorada y repujada. Ha sido identificada por Yayoi Kawamura como obra del platero Juan Sabino Collas (h. 1747-1787 activo), hijo y sucesor del maestro platero procedente de Burdeos Francisco Co- llas $^{42}$. En ella se representa al cordero místico, con cruz, asentado sobre las Sagradas Escrituras y coronado por nubes, de las que irradian los rayos propios del Espíritu Santo.

\section{A modo de conclusión}

Tras este breve análisis de los bienes muebles de la iglesia de Santa María de Sábada, podemos afirmar que el templo fue construido y dotado acorde a las últimas tendencias artísticas del momento, aspecto muy digno de señalar, a pesar de ser una simple parroquia rural. La razón se debe buscar en el patrocinio de los lastrinos emprendedores que lograron adquirir importantes riquezas en sus empeños profesionales fuera de Asturias. Por otra parte, cabe señalar que desgraciadamente no se conservan muchas de las piezas que en ella se veneraron, cuya existencia hemos podido rescatar de su total olvido gracias a inventarios y otros documentos conservados por los herederos de las familias que actuaron como mecenas en la villa en el siglo XVIII.

Esta aportación forma parte de un mayor y más amplio estudio sobre la villa de Lastres durante los siglos XVII y XVIII ${ }^{43}$.
40 Agradezco al profesor Julio J. Polo Sánchez su sugerencia.

${ }^{41}$ AHA, PN de Villaviciosa, Caja 1335/04, no 74 (Contrato ante José Lorenzo Isla, 22 de julio de 1793).
42 KAWAMURA, Y., Arte de la platería en Asturias: periodo barroco, Oviedo, Real Instituto de Estudios Asturianos, 1994, pp. 104 y 142.

Agradezco a la profesora Kawamura su ayuda y disponibilidad durante todo este estudio, así como sus múltiples sugerencias.

43 Se espera una pronta publicación del trabajo completo en breve. 